\title{
DISEMINASI TEKNOLOGI MESIN PENCACAH PELEPAH LIMBAH SAWIT SEBAGAI PAKAN ALTERNATIF TERNAK SAPI DI DESA KERAPUH SERDANG BEDAGAI
}

\author{
Puji Ratno ${ }^{1}$, Baharuddin ${ }^{2}$, Dedy Husrizal Syah ${ }^{3}$, Irfandi $^{4 *}$, \\ Deo Demonta Panggabean ${ }^{5}$
}

\author{
Jurusan Fisika, Fakultas Matematika dan Ilmu Pengetahuan Alam, \\ Universita Negeri Medan, Indonesia \\ irfandi@unimed.ac.id
}

\begin{abstract}
Abstrak
Kegiatan ini dilaksanakan di Mitra 1 Kelompok Ternak Anugrah dan Mitra 2 Kelompok Peternak Makmur, kedua mitra berada di Desa Kerapuh Kecamatan Dolok Masihul Kabupaten Serdang Bedagai. Pemilihan lokasi ini dikarenakan di desa tersebut terdapat masyarakat yang sebagian besar merupakan pelaku usaha peternakan, pertanian dan karyawan perkebunan sawit yang mempunyai usaha sampingan sebagai Peternak. Permasalahan tersebut meliputi : 1)Kurangnya ketersediaan pakan ternak sehingga mempengaruhi produksi usaha 2) Dilarangnya bagi para peternak untuk mengambil rumput/menggembalakan hewan di perkebunan 3) Terbatasnya pengetahuan petani tentang Pakan hewan ternak selain rumput dan masih rendahnya pemanfaatan pakan ternak ruminansia dari limbah daun ubi dan jagung, 4) tidak adanya alat TTG untuk pembuatan pakan pakan ternak ruminansia . Luaran dari program antara lain : (1)Alat TTG Pencacah pelepah sawit, (2) Bisnis Plan, (3)Pemasaran IT Web, (4)Jurnal, (5)Media Massa/Online. Dalam pencapaian tujuan pada kegiatan ini, maka Metode yang digunakan pada Kelompok Peternak sebagai mitra kerja dengan strategi pendekatan secara kekeluargaan, mengajak partisipasi dalam program desiminasi teknologi, Pelatihan dan pendampingan serta workshop.
\end{abstract}

Kata kunci: Pakan, Ternak, Ruminasia, TTG

This activity was carried out in Partner 1 Anugrah Cattle Group and Partner 2 Makmur Farmers Group, both partners are in Kerapuh Village, Dolok Masihul District, Serdang Bedagai Regency. The location was chosen because in the village there are people who are mostly Cattle, agricultural and oil palm plantation employees who have a side business as breeders. These problems include: 1) Lack of availability of animal feed which affects business production 2) It is prohibited for breeders to take grass / grazing animals on plantations 3) Limited knowledge of farmers about animal feed other than grass and the low utilization of ruminant animal feed from cassava leaves and maize, 4) absence of TTG equipment for making ruminant feed. The output of the program includes: (1) TTG Tool for chopping palm fronds, (2) Business Plan, (3) IT Web Marketing, (4) Journals, (5) Mass Media / Online. In achieving the objectives of this activity, the method used in the Farmer Group as partners is a family approach, inviting participation in technology dissemination programs, training and mentoring and workshops.

Keywords:Feed,Cattle, Ruminasia, TTG

\section{Pendahuluan}

Kecamatan Dolok Masihul merupakan kecamatan yang memiliki jumlah penduduk terbesar ke 3 (tiga) setelah Kecamatan Perbaungan dan Kecamatan Sei Rampah di Kabupaten Serdang Bedagai. Jumlah penduduk
Kecamatan Dolok Masihul pada tahun 2020 berjumlah 49.751 jiwa dengan komposisi jumlah penduduk lakilaki 24.570 jiwa dan perempuan 25.181 jiwa dengan sex ratio 97,57 persen. Laju pertumbuhan penduduk dari tahun 2010 ke tahun 2020 sebesar 0,39 persen dimana 
laju pertumbuhan penduduk tertinggi yaitu di Desa Kerapuh sebesar 1,17 persen, sedangkan laju pertumbuhan penduduk terendah yaitu di Desa Batu 13 dan Desa Pekan Kemis yaitu sebesar 0,21 persen.

Desa Kerapuh jika ditinjau dari aspek ekonomi masyarakatnya dapat digolongkan sebagai masyarakat produktif, akan tetapi masih memiliki tingkat kesejahteraan yang masih jauh dari sejahtera. Hal ini terungkap bila kita lihat dari data tentang ragam profesi dan kondisi ekonomi desa, karena profesi penduduk masih didominasi oleh Petani dan Peternak sebanyak 630 jiwa. Kebanyakan pertanian yang dilakukan adalah sistem berladang dengan menanam pohon-pohon yang dapat berproduksi dalam waktu yang lama. Sebagian besar para petani mempunyai usaha juga sebagai peternak yaitu sapi, kambing serta ayam dan bebek. Selanjutnya disusul oleh karyawan perkebunan kelapa sawit swasta, karyawan perkebunan didominasi oleh perkebunan PT. Bridgestone dan perkebunan kelapa sawit PT.Socfindo.

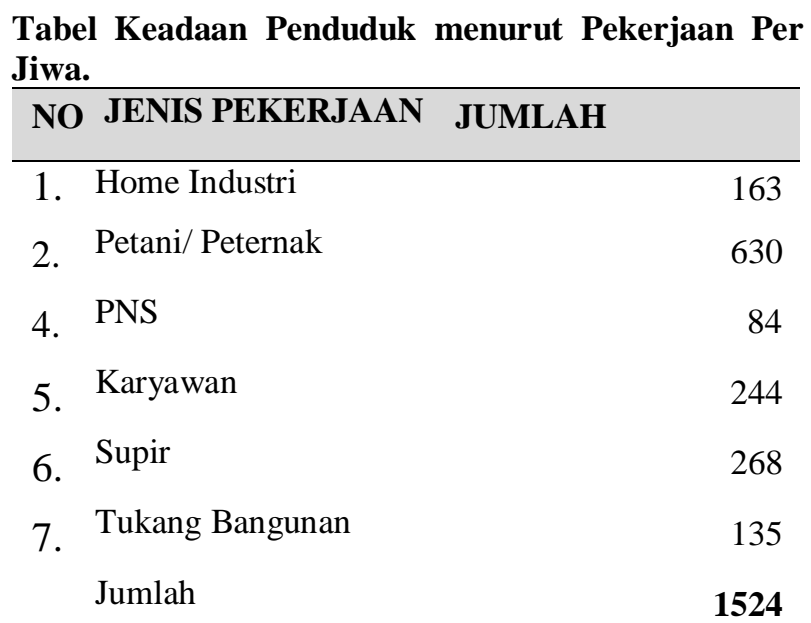

Sumber data diambil dari : Monografi Desa Kerapuh tahun 2017

Dari data monografi desa dapat kita lihat jenis pekerjaan yang paling dominan adalah petani/peternak sebesar 630 jiwa. Para peternak masih mengandalkan pakan rumput hijau sebagai pakan ternak. Selain itu jumlah pendududk dengan profesi sebagai Petani Peternak menempati posisi yang cukup besar di bandingkan dengan profesi lainnya. Hal ini bukan tanpa alasan dikarenakan dikelilingi oleh perkebunan karet dan sawit yang dimiliki oleh PTPN IV dan swasta maka banyak peternak yang menggantungkan hidupnya dari rumput yang ada diperkebunan tersebut dikarenakan luas perkebunan yang mengelilingi desa dari hulu ke hilir. Inilah yang menyebabkan banyaknya masyarakat menjadi peternak di Desa Kerapuh. Akan tetapi hal tersebut tidak berlangsung lama baru-baru ini di tahun 2019 (Wawancara dengan Amirsyah Ketua
kelompokAnugrah, 1 April 2020), perkebunan membuat kebijakan baru antara lain :

1. Tidak dibenarkan lagi warga mengembalakan ternak di areal perkebunan karena dianggap dapat merusak tanaman dan membuat lahan perkebunan menjadipadat

2. Dalam jangka waktu 1 bulan sekali diadakan penyemprotan rumput sehingga rumput tidak dapat tumbuh dan walaupun ada rumput akan tetapi, sudah tercemar pestisida sehingga membahayakanternak

3. Warga yang tinggal di kompleks perkebunan atau Pondok dilarang memelihara ternak baik sapi maupun kambing.

Kendati demikian permasalahan petani tidak terhenti sampai disitu karena intensitas pertumbuhan rumput tidak kontiniu setiap saat, dan juga terbatas dalam memperoleh rumput dalam jumlah besar dan bila di beli setiap 1 ikat rumputdengan massa sekitar $40 \mathrm{~kg}$ peternak harus mengeluarkan biaya sebesar Rp. 50.000/ ikatnya.

Oleh karena itu diperlukan teknologi pemanfaatan pelepah dan batang kelapa sawit yang melimpah dari perkebunan sekitar desa tersebut, untuk dapat di jadikan suatu yang lebih berharga yaitu menjadi Alternatif Pakan Ternak ruminansia dengan kualitas yang baik tentu akan lebih menguntungkan bukan hanya bagi petani tersebut yang notabene merupakan peternak.Pakan ternak ruminansiase bagi solusi bagi peternak dalam jumlah besar yang ada di Desa Kerapuh. Setiap 1 ton limbah batang dan pelepah sawit yang dihasilkan apabila diolah menjadi pakan ruminansia maka dapat disimpan untuk persediaan pakan ternak (40-50 ekor) dalam setahun.

\section{Profil Mitra}

Mitra 1 Program Teknologi yang di Diseminasi pada Masyarakat ini adalah Kelompok Ternak Anugrah yang diketuai oleh Amirsyah. Kelompok ini berada di Desa Kerapuh Kecamatan Dolok Masihul yang berjarak \pm 68 $\mathrm{km}$ dari Universitas Negeri Medan dan dapat ditempuh dengan angkutan umum selama 2 jam sampai kelokasi. Kelompok ini memiliki anggota kelompok sebanyak 20 orang, dengan 25 kandang (Rumah ternak) ternak sapi. Dengan jumlah hewan ternak \pm 220 ekor ternak sapi yang tersebar di dua puluh lima kandang yang dimiliki oleh masing-masing peternak. Kandang-kandang tersebut tersebar di dusun-dusun Desa Kerapuh dan kecamatan Dolok masihul, Hewan yang diternakkan sebagian besar adalah lembu (sapi). 

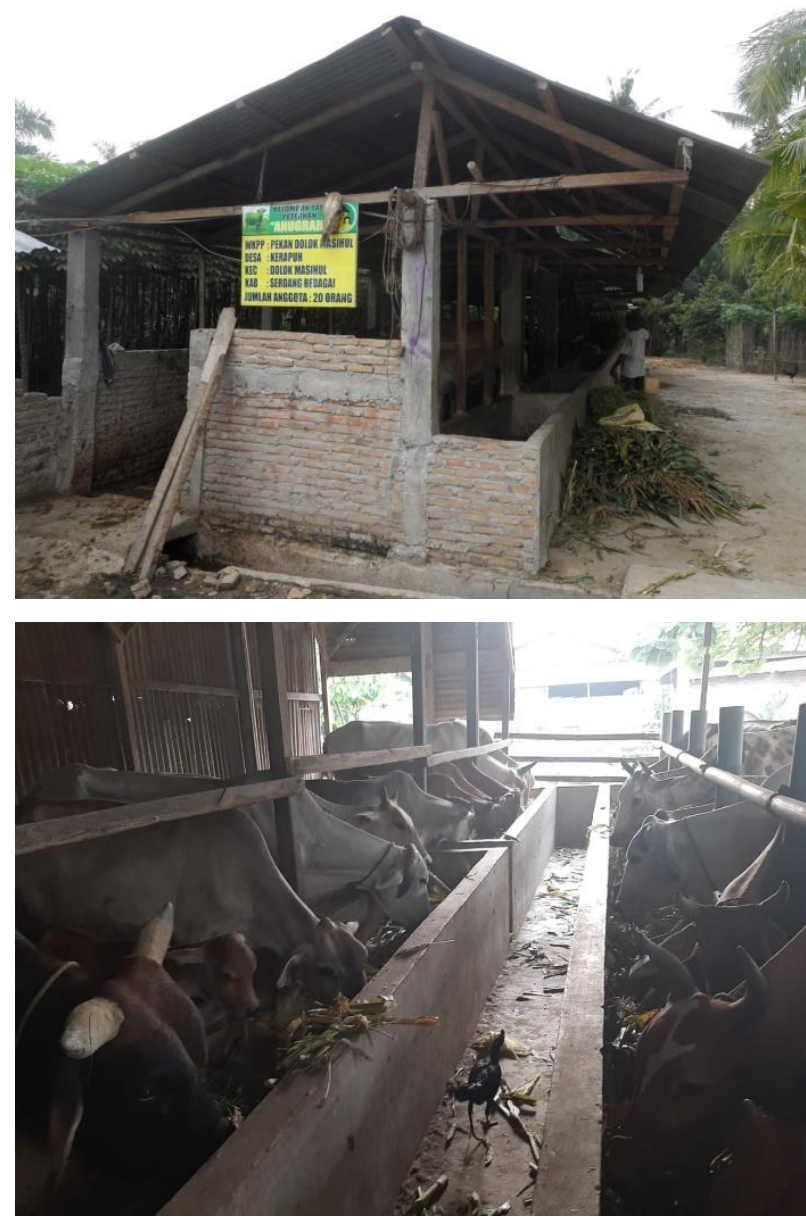

Gambar. Kandang Sapi Mitra 1 Kelompok Ternak Anugerah

Selama ini Mitra 1, Kelompok Peternak Ternak Anugrah tersebut tidak mengembalakan ternak diareal perkebunan hanya mengambil rumput akan tetapi dengan kebijakan Perkebunan yang melarang menggembalakan di areal lingkungan Perkebunan tersebut selain mencari pakan dari petani untuk menutupi pakan ternak dengan cara membeli dedak ataupun serbuk tongkol jagung untuk pengganti pakan sehingga hal ini membebani kelompok Peternak Ternak Anugerah dalam operasionalnya karena tongkol jagung di jual Rp. 3000/Kg sementara dalam 1hari memerlukan pakan sampai $100 \mathrm{~kg}$ tongkol jagung halus. Pendapatan kelompok didapatkan dari hasil penjualan sapi/lembu. Lembu biasanya pada umur 1 tahun sudah menghasilkan anakan, dalam 6 bulan anakan sudah dapat dijual seharga 12 juta/ekor, dalam setiap bulan rata-rata 3 ekor yang terjual sehingga didapatkan penghasilan 30-35 juta/ Bulan.

Mitra 2 Program Teknologi yang di Diseminasi pada Masyarakat ini adalah Kelompok Peternak Kerapuh Makmur diketuai oleh Suyanto. Kelompok ini berada di Dusun II Desa Kerapuh Kecamatan Dolok Masihul Kabupaten Serdang Bedagai yang berjarak \pm 72 km dari
Universitas Negeri Medan dan dapat ditempuh dengan angkutan umum selama \pm 2 jam sampai kelokasi. Kelompok ini memiliki anggota kelompok sebanyak 20 orang, dengan 20 kandang ternak sapi/lembu. Dengan jumlah hewan ternak \pm 125 ekor ternak sapi/lembu yang sebagian besar adalah sapi/lembu limosin dan sapi/lembu lokal.


Gambar. Kandang Sapi Mitra 2 Kelompok Ternak Makmur

Kelompok ternak ini hanya melakukan usaha jual beli sapi/lembu yang biasanya banyak dipesan masyarakat untuk keperluan qurban, dan konsumsi daging, hajatan dan aqiqah, karena bentuk postur dagingnya relative lebih banyak dibandingkan dengan jenis lembu/sapi yang lainya. Serta untuk pakannya pun biasanya sapi/lembu tersebut digembalakan di Perkebunanan tersebut. akan tetapi dengan kebijakan Perkebunan tersebut selain mencari pakan jauh keluar desa untuk mendapatkan rumput maupun daunan hijau segar hal ini mengakibatkan tidak efisien waktu dan tenaga serta menguras biaya operasional kendaraan. Pendapatan kelompok didapatkan dari hasil penjualan sapi/lembu. Penjualan setiap bulan rata-rata 1 atau 2 ekor yang terjual sehingga didapatkan penghasilan 2025 juta/Bulan. 


\section{Permasalahan Mitra}

Justifikasi Pengusul Bersama Mitra dalam MenentukanPersoalan

Solusi yang ditawarkan kepada Kedua Mitra dalam pelaksanaan Program Produk Teknologi yang Didiseminasikan disepakati akan menjawab permasalahan utama yang dihadapi mitra. Untuk dapat menganalisa permasalahan yang dihadapi oleh mitra maka tim pengabdi dengan Mitra, telah menentukan justifikasi pengusul bersama mitra, untuk menyelesaikan permasalahan prioritas dan menyepakati kegiatan yang akan dilakukan sebagaiberikut:

1. Produksi daging ternak menurun dikarenakan pakan yang langka, sehingga berimplikasi pada penghasilanpeternak.

2. Pemasaran produk masih konvensional hanya terbatas pada agen dan informasi orang ke orang, peternak hanya menunggun konsumen yang datang

3. Manajemen pengelolaan usaha hanya berorientasi pada ketua dan anggota yang lain aktif apabila ada kegiatan seremonial atau bantuan.

4. Pembukuan keuangan kelompok masih sederhana hanya modal kepercayaan dan dicatat tanpa ada analisis maupun pembukuankeuangan

5. Belum adanya keterampilan mitra pada teknologi tepat guna untuk membuatpakanruminansia agar pakan dapat disimpan untuk persediaan dalam jangka waktu lama.

6. Pemanfaatan teknologi untuk pencacah limbah pelepah sawit sebagai pakan alternatif yang banyak dihasilkan dari perkebunan disekitardesa.

7. Biaya produksi dan pengeluaran tidak tercatat dengan detail sehingga sulit dalam menentukanharga.

8. Tidak adanya pengelolaan limbah ternak baik cair dan padat untuk menghasilkan pendapatan tambahankelompok

9. Pemasaran masih manual tidak menggunakan Media Digital dan kebanyakan hanya melalui agen ke agen dari mulut kemulut.

Dari sekian permasalahan yang sedang dihadapi oleh masyarakat di desa Kerapuh , kami berpendapat bahwa penanggulangan awal yang harus segera dilakukan adalah Pengadaan alat Teknologi Tepat Guna dalam hal pengadaan pakan ternak dan pemasaran ternak juga untuk membantu produksi usaha mitra.

\section{BAHAN DAN METODE}

Untuk mencapai tujuan dari kegiatan ini metode yang digunakan adalah Pelatihan dan Pendampingan kepada masyarakat serta strategi pendekatan secara kekeluargaan, mengajak partisipasi dalam program desiminasi ini.

Tahapan pelaksanaan Solusi dari

\section{PermasalahanMitra}

Aspek-aspek tahapan pelaksanaan kegiatan pengusul terhadap mitra dapat dijelaskan sebagai berikut :

1. Melaksanakan observasi dan identifikasi permasalahan yang dihadapai mitra 1 dan2

2. Menyepakati permasalahan yang paling prioritas yang dihaapi oleh mitra untuk di dapatkan solusi dari permasalahantersebut.

3. Melaksanakan pelatihan dan pendampingan pembuatan pakan Ruminansia untuk meningkatkan produksi daging ternak sehingga meningkatkanpendapatan

4. Memberikan alat TTG dan melaksanakan workshop penggunaan alat teknologi tepat guna pembuatan pakan Ruminansia dan memberikan pelatihan penggunaan alat pencacah rumput

5. Pemberian pendidikan dan pelatihan manajemen usaha dengan mengoptimalkan fungsi Kelompok Peternak Mitra, meliputi pembuatan bisnis plan dan penyusunan laporan keuangan.

6. Memberikan pendidikan dan pelatihan pembuatan proposal kredit agar dapat melakukan pinjaman di bank atau KUR

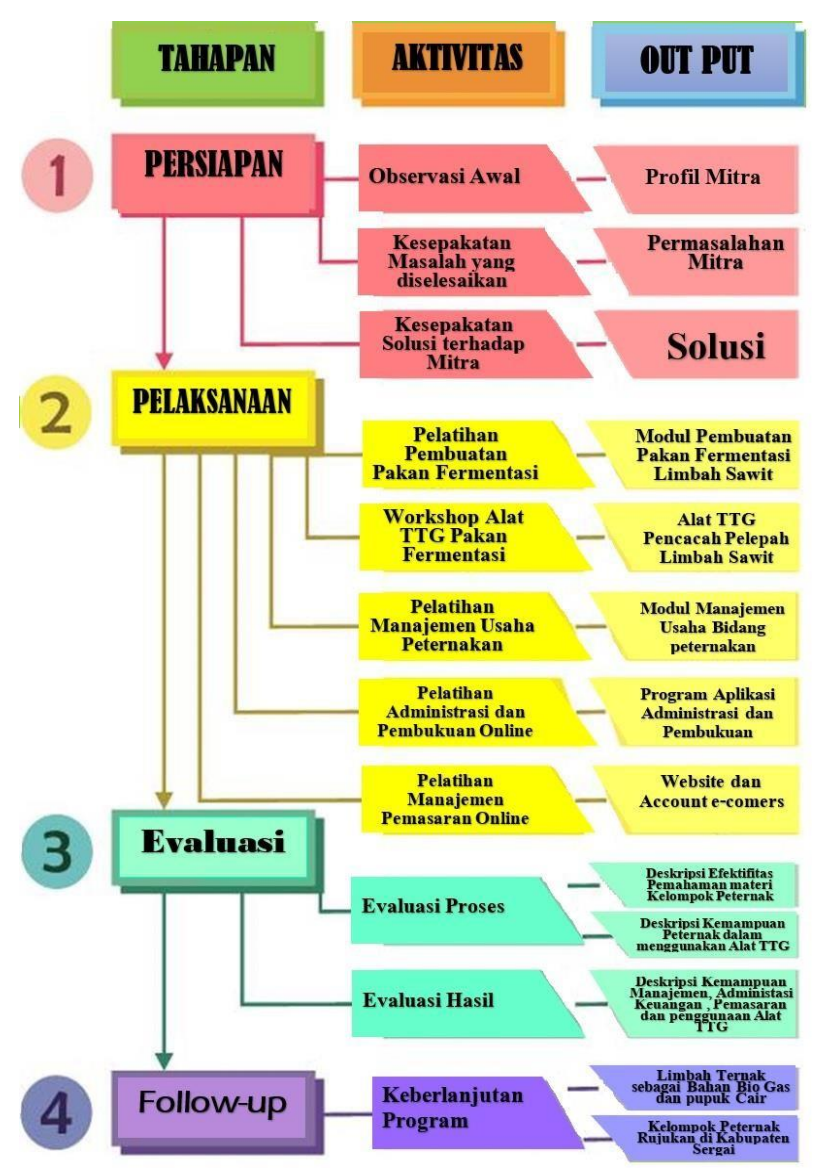




\section{Gambar. Tahapan Pelaksanaan Kegiatan dan Solusi Pada Mitra.}

\section{HASIL DAN PEMBAHASAN}

Pengabdian Program Teknologi yang di Diseminasi pada Masyarakat (PDTM) Kelompok Peternak Desa KerapuhKecamatan Dolok MasihulKabupaten Serdang Bedagaiini telah dilaksanakan sejak bulan Agustus2020. Adapun kegiatan-kegiatan yang telah dilakukan meliputi tahapan sebagai berikut:

\section{Persiapan}

a. Persiapan (koordinator tim pelaksana dengan LPM dan Usaha mitra) yang dilaksanakan pada tanggal27 Agustus2020

b. Tim pengabdi melakukan Pengurusan perijinan kepada aparatur desa yang dijadikan lokasi pengabdian

c. Ketua tim bersama anggota pengabdi Penyusunan dan jadwal kegiatan dan melakukan pembagian kerja yang dilaksanakn pada tanggal 29 Agustus2020.

Operasional Kegiatan

a. Tim pengabdi melakukan Temu usaha dan Focus Group Discusion (FGD) untuk pemantapan kegiatan yang dilaksanakan pada tanggal 2 September 2020

b. Pengumpulan bahan dan peralatan yang dibutuhkan dalam kegiatan Kelompok Peternak Desa Kerapuh Kecamatan Dolok Masihul Kabupaten Serdang Bedagai yang dilaksanakan pada tangga 14 September 2020

c. Pelatihan pembukuan keuangan dan manajemen Usaha untuk memberikan pemahaman kepada kelompok dalam mengelola usaha dan juga memanage usaha agar semua administrasi dan system kauangan lebih transparan dan dapat di rasakan keuntungan oleh anggota kelompok.

d. Menyerahkan alat pembuatan mesin pencacah rumput yang digunakan sebagai alat pencacah pakan rumanisa yang digunakan sebagai bahan pakan fermentasi pada hewan ternak yang dilakukan oleh Puji Ratno, S.Si., M.Pd.

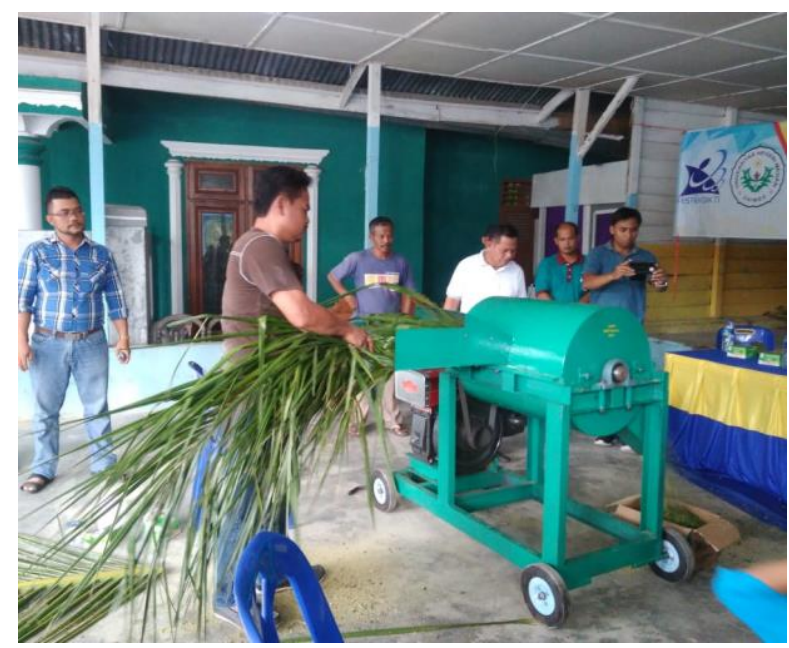

Gambar : Proses pelatihan penggunaan Mesin cacah

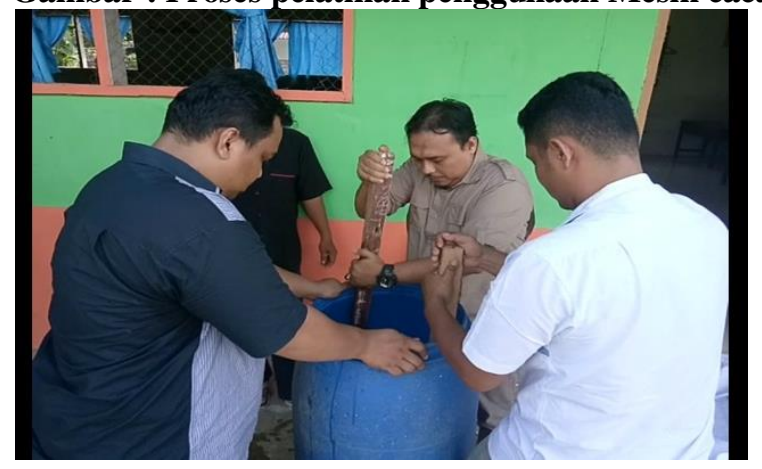

Gambar: Proses Pelatihan pembuatan Pakan Fermentasi

Disamping capaian diatas tim pengabdi juga telah menghasilkan satu produk teknologi tepat guna berupa mesin pencacah pakan dengan menggunakan tenaga mesin solar 12 PK. Pisau mesin dibuat dari bahan baja agar dapat menghancurkan pelepah kelapa sawit dan ketajaman pisau dapat bertahan lama. Desain pisau dibuat seperti sisir keliling dengan tujuan menghasilkan bubuk yang lebih halus sehingga lebih mudah untuk diproses lebih lanjut dengan teknik fermentasi.

Program Teknologi yang di Diseminasi pada Masyarakat ini memiliki Tim yang solid dan kompeten serta dapat bekerjasama dengan baik. Sarana workshop tempat proses pembuatan alat mesin pembuat pakan fermentasi memiliki fasilitas yang baik sehingga proses pembuatan alat dapat dilakukan di satu tempat. Mitra dari Program Teknologi yang di Diseminasi pada Masyarakat memiliki kemampuan komunikasi yang baik dan antusias yang tinggi sehingga berperan aktif pada proses pelaksaan Program Teknologi yang di Diseminasi pada Masyarakat. Dalam pelaksanaaan kegiatan partisipasi mitra sangat baik dalam dalam meyiapkan 
peralatan praktek yang dibutuhkan selama kegiatan berlangsung.

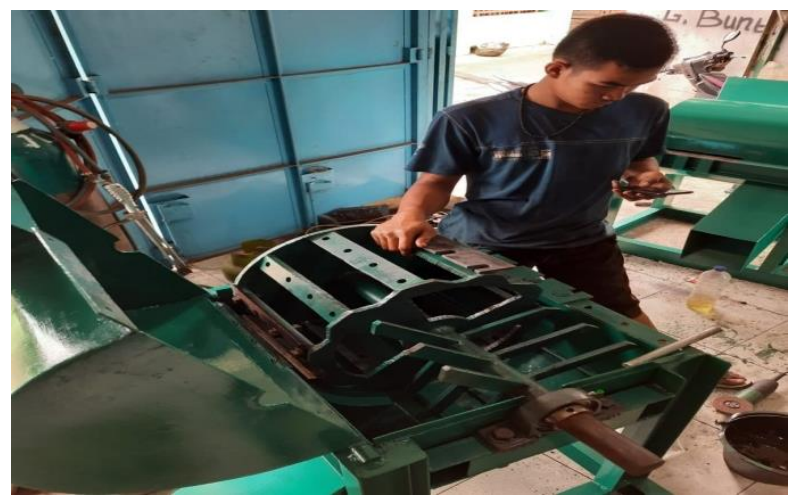

Gambar : Pemasangan Pisau Mesin cacah.

Perubahan Dalam Penerapan Program Pada mitra

\begin{tabular}{|c|c|c|}
\hline Indikator & Awal & Akhir \\
\hline $\begin{array}{l}\text { Limbah } \\
\text { Pelepah } \\
\text { Sawit }\end{array}$ & $\begin{array}{l}\text { Mengganggu } \\
(0 \%) \\
\text { Dibuang dan } \\
\text { durinya } \\
\text { membahayakan } \\
\text { warga } \\
\text { lingkungan }\end{array}$ & $\begin{array}{l}\text { Bermanfaat }(80 \%) \\
\text { Di manfaatkan sebagai } \\
\text { Pakan Ternak }\end{array}$ \\
\hline $\begin{array}{l}\text { Dengan } \\
\text { diberikan } \\
\text { Mesin } \\
\text { Pencacah } \\
\text { Pelepah } \\
\text { sawit } \\
\end{array}$ & Tidak ada & $40 \mathrm{Kg} /$ Hari \\
\hline $\begin{array}{l}\text { Dengan di } \\
\text { Berikan } \\
\text { Pelatihan } \\
\text { Manajemen } \\
\text { dan } \\
\text { Adminitrasi } \\
\text { Usaha } \\
\end{array}$ & $\begin{array}{l}\text { Usaha } \\
\text { dilakukan } \\
\text { secara } \\
\text { tersendiri } \\
\text { hanya ketua } \\
\text { yang berperan }\end{array}$ & $\begin{array}{l}\text { Usaha dilakukan } \\
\text { secara berkelompok } \\
\text { dan dan sudah mulai } \\
\text { menerapkan } \\
\text { pembagian tugas }\end{array}$ \\
\hline $\begin{array}{l}\text { Dengan di } \\
\text { Berikan } \\
\text { Pelatihan } \\
\text { Keuangan } \\
\text { Usaha }\end{array}$ & $\begin{array}{l}\text { Pencatatan } \\
\text { keuangan tidak } \\
\text { tercatat dan } \\
\text { masing-masing } \\
\text { personal yang } \\
\text { menyusun }\end{array}$ & $\begin{array}{l}\text { administrasi keuangan } \\
\text { tercatat dalam setiap } \\
\text { kegiatan peristiwa }\end{array}$ \\
\hline
\end{tabular}

\begin{tabular}{|l|l|l|}
\hline $\begin{array}{l}\text { Setelah di } \\
\text { berikan } \\
\text { mesin } \\
\text { pencacah } \\
\text { pakan }\end{array}$ & $\begin{array}{l}\text { Hanya } \\
\text { mengandalkan } \\
\text { rumput di } \\
\text { sekitar desa }\end{array}$ & $\begin{array}{l}\text { Memanfaatkan limbah } \\
\text { batang ubi, limbah } \\
\text { batang jagung dan } \\
\text { limbah batang sawit }\end{array}$ \\
\hline $\begin{array}{l}\text { Setelah di } \\
\text { berikan } \\
\text { pelatihan } \\
\text { fermentasi } \\
\text { pakan } \\
\text { ternak }\end{array}$ & $\begin{array}{l}\text { Pakan hanya } \\
\text { bertahan 3-4 } \\
\text { hari }\end{array}$ & $\begin{array}{l}\text { Pakan dapat bertahan } \\
\text { 3-4 Bulan }\end{array}$ \\
\hline $\begin{array}{l}\text { Pendapatan } \\
\text { bersih } \\
\text { usaha } \\
\text { Perbulan }\end{array}$ & $\begin{array}{l}\text { Rp. 800.000,-- } \\
\text { Rp. 1.000.000,- }\end{array}$ & Rp. 1.500.000,- - Rp. \\
$2.000 .000,-$ \\
\hline
\end{tabular}

\section{KESIMPULAN}

Pengabdian PTDM Kelompok Peternak Desa Kerapuh telah dapat dijalankan dengan baik dan tanpa halangan yang berarti. Dengan kerjasama tim pengabdian yang baik dan peran serta aktif dari penyuluh/narasumber dalam kegiatan pengabdian ini maka semuanya telah berjalan sesuai yang diharapkan dan harapannya dapat memberikan manfaat bagi mitra pengabdian masyarakat dalam keberlanjutan usaha dan Produksi Usaha Peternak pada kedua kelompok UMKM Mitra. Pengabdian yang kami lakukan ini telah sampai pada tahapan dilaksanakannya kegiatan penyuluhan tentang motivasi usaha Peternak dan produk-produk olahan dari peternakan tersebut. Kegiatan pengabdian ini berdampak pada peningkatan pengetahuan masyarakat dalam mengolah bahan pakan alternative untuk menyelesaikan kendala yang mereka hadapi. Disamping itu adanya peningkatan pendapatan kelompok usaha ternak sapi dimana sebelumnya sudah mengalami kelesuan akibat kesulitan dalam pengadaan pakan yang baik.

\section{UCAPAN TERIMA KASIH}

Terima kasih kami ucapkan kepada Kementrian Riset dan Tehnologi Republik Indonesia, yang telah membiayai kegiatan deseminasi teknologi tepat guna bagi kelompok ternak yang ada di Desa Kerapuh, Kecamatan Dolok Masihul, Kabupaten Deli Serdang. Mudah mudahan kegiatan yang telah dilaksanakan dapat memberikan pengetahuan dan manfaat bagi masyarakat peternak untuk meningkatkan produksi dan meningkatkan kesejahteraan ekonomi nya. Ucapan terima kasih kami kepada Bapak Rektor Universitas Negeri Medan Bapak Dr. Syamsul Gultom, M.Kes, yang telah memberikan dukungan kepada kami untuk dapat melaksanakan kegiatan kami. Kepada bapak Prof. Dr. Baharuddin, S.T, M.Pd selaku Ketua Lembaga Penelitian dan Pengabdian Masyarakat UNIMED, yang dengan sabar selalu memotivasi dan mengevalusi 
kegiatan yang telah kami lakukan, kami ucapkan banyak terima kasih. Tak lupa pula kami ucapkan terima kasih kepada bapak Ahmad selaku kepala Desa Kerapuh yang telah menerima kami dan memberikan masukan dalam pelaksanaan kegiatan kami di Desa Kerapuh. Kepada kelompok ternak yang telah mengikuti kegiatan kami ucapkan ribuan terima kasih telah dengan sabar mengikuti setiap kegiatan yang telah kami lakukan.

\section{DAFTAR PUSTAKA}

Almar, Buchori, 2001, Kewirausahaan., Bandung : Alfabeta.

David, Downey dkk. 1992. Manjemen Agribisnis. Jakarta : Erlangga

Drucker, P.F, 1996, Konsep Kewirausahaan Era Globalisasi. Jakarta : Erlangga Terjemahan

Irfandi, 2015, Peningkatan Pendapatan Anggota Kelompok UPPKS Manalagi Kecamatan Bilah Hulu Labuhan Batu Dengan Menggunakan Oven Serbaguna, Jurnal Lembaga Pengabdian Kepada Masyarakat, volume 21 No. 80 tahun XXI Juni 2015, Unimed. Halaman 33-38

Irfandi, I., Hidayat, T., \& Salman, R. (2018). Pemberdayaan Usaha Kecil Menengah Kuliner Roti di Kabupaten Simalungun. Jurnal Pengabdian Kepada Masyarakat, 24(2), 661-670
Irfandi, I., Ritonga, W., \& Sabani, S. (2015). Pemberdayaan UPPKS Bintang Kecamatan Batang Kuis Berbasis Teknologi Tepat Guna. Jurnal Pengabdian Kepada Masyarakat, 21(82), 53-59

Irfandi, I. (2014). Peningkatan Pendapatan Anggota Kelompok UPPKS Manalagi Kecamatan Bilah Hulu Labuhan Batu Dengan Menggunakan Oven Serbaguna. Jurnal Pengabdian Kepada Masyarakat, 21(80), 33-38

Irfandi, I., Hidayat, T., \& Azis, A. C. K. (2018). Optimalisasi Manajemen Administrasi Dan Pembukuan Keuangan Pengerajin Anyam Khas Melayu Pesisir Pantai Cermin. Prosiding Konferensi Nasional Pengabdian Kepada Masyarakat dan Corporate Social Responsibility (PKM-CSR), 1, 1610-1619

Nasution H.A. Bustanul A.N Mukhammad S., 2001, Membangun Spirit Entrepreneur Muda Indonesia. Jakarta : Gramedia.

Ridwan, A. S. 2013. Pembinaan Masyarakat Berbasis IPTEKS, Citapustaka Media Perintis, Bandung.

Sularso dan Saga. 1983. Elemen Mesin. Jakarta : Pradnya Paramita

Suyanto, 2010. Multimedia: Alat untuk Meningkatkan Keunggulan Bersaing, Jakarta press 
